Int. J. Electrochem. Sci., 12 (2017) 3941 - 3949

\title{
One-pot Synthesis of Cuprous Oxide-Reduced Graphene Oxide Nanocomposite as an Anode Material for Lithium Ion Battery
}

Yi Lu ${ }^{1,2, *}$, Tao Wang $^{2}$, Zhaojun Tian ${ }^{2}$ and Qing Ye $e^{2}$

${ }^{1}$ Hunan University of Science and Technology, Work Safety Key Lab on Prevention and Control of Gas and Roof Disasters for Southern Coal Mines, Xiangtan, Hunan 411201, China

${ }^{2}$ Hunan University of Science and Technology, School of Resource, Environment and Safety Engineering, Xiangtan, Hunan 411201, China

*E-mail: 1uyihnust@163.com

doi: $10.20964 / 2017.05 .65$

Received: 23 February 2017 / Accepted: 4 April 2017 / Published: 12 April 2017

With the simultaneous reduction of $\mathrm{Cu}^{2+}$ ions and $\mathrm{GO}$ by ethylene glycol, this work explores the convenient and one-pot preparation of porous cuprous oxide nanoparticles on reduced graphene oxide $\left(\mathrm{Cu}_{2} \mathrm{O}-\mathrm{RGO}\right)$. A series of measurements were applied for the characterization of the surface morphology, crystal structure and basic chemical elements of synthesized nanocomposite. An increase of initial discharge capacity to $2038 \mathrm{mAh} / \mathrm{g}$ was observed for the battery due to the synergetic effect of wrinkled graphene \& copper oxide. This study conducts the impedance spectroscopy for obtaining charge transfer resistance of the electrode, with the results analysed herein.

Keywords: One-pot; Graphene; Cuprous oxide; Lithium ions; Battery

\section{FULL TEXT}

(C) 2017 The Authors. Published by ESG (www.electrochemsci.org). This article is an open access article distributed under the terms and conditions of the Creative Commons Attribution license (http://creativecommons.org/licenses/by/4.0/). 